\title{
DAS GASGLÜHLICHT
}





\title{
DAS GASGLÜHLICHT
}

SEINE GESCHICHTE

HERSTELLUNG UND ANWENDUNG

\author{
EIN HANDBUCH
}

FUUR DIE BELEUCHTUNGSINDUSTRIE

voN

DR. C. RICHARD BÖHM

MIT 379 ABBILDUNGEN

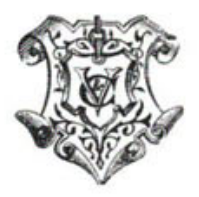

LEIPZIG

VERLAG VON VEIT \& COMP.

1905 
Druck von Metzger \& Wittig in Leipzig 


\section{HERRN \\ Professor Dr. HANS BUNTE}

VEREHRUNGSVOLL GEWIDMET 
